\title{
ANALISIS PENDAPATAN DAN TINGKAT KESEJAHTERAAN RUMAH TANGGA PETERNAK SAPI POTONG KELOMPOK TERNAK LIMOUSIN DESA ASTOMULYO KECAMATAN PUNGGUR KABUPATEN LAMPUNG TENGAH
}

\author{
Analysis of Income and Breeder Household Welfare Level of Limousin Livestock Group in Astomulyo \\ Village, Punggur Sub District, Central Lampung Regency
}

\author{
Annisa Dwi Martha, Dwi Haryono, Lina Marlina* \\ Department of Agribusiness, Faculty of Agriculture, University of Lampung \\ Jl. Soemantri Brodjonegoro No. 1, Gedong Meneng, Rajabasa, Bandar Lampung 35145 \\ *E-mail : lina.marlina@fp.unila.ac.id
}

Submitted : September 25, 2019 Accepted : July 22, 2020

\begin{abstract}
ABSTRAK
Penelitian ini bertujuan untuk menganalisis pendapatan peternak sapi, pendapatan rumah tangga peternak sapi dan tingkat kesejahteraan peternak sapi anggota Kelompok Ternak Limousin. Penelitian ini dilakukan secara sengaja pada Januari-Februari 2019 di Desa Astomulyo, Kecamatan Punggur, Kabupaten Lampung Tengah, menggunakan metode survei. Ada 45 responden yang diambil dengan menggunakan Simple Random Sampling. Data dianalisis secara kuantitatif dan kualitatif dengan menggunakan analisis pendapatan (Revenue-Cost Ratio-R/C), analisis pendapatan rumah tangga, dan tingkat kesejahteraan rumah tangga peternak berdasarkan kriteria Badan Pusat Statistik. Hasil penelitian menunjukkan bahwa pendapatan rata-rata peternak berdasarkan biaya tunai dan total biaya sebesar Rp138.882.134,78 per tahun dan Rp132.405.206,29 per tahun. Usaha ternak sapi layak dan menguntungkan karena memperoleh rasio penerimaan dengan biaya tunai dan total biaya lebih dari satu $(\mathrm{R} / \mathrm{C}>1)$ yaitu 1,44 dan 1,41 . Usaha ternak sapi memberikan kontribusi terbesar pada pendapatan rumah tangga sebesar $94,38 \%$, sedangkan sisanya berasal dari kegiatan usahatani (on farm), kegiatan yang masih ada kaitannya dengan pertanian (off farm), dan kegiatan non pertanian (non farm). Berdasarkan kriteria BPS bahwa 91,11\% rumah tangga peternak di Desa Astomulyo berada dalam kategori sejahtera.
\end{abstract}

Kata kunci : Analisis pendapatan, Kesejahteraan rumah tangga, Peternak sapi potong.

\begin{abstract}
This study aims to analyze the income of breeder income, breeder household income, and welfare level of breeder the members of Limousin Livestock Group. This research was carried out intentionally in January-February 2019 in Astomulyo Village, Punggur Sub District, Central Lampung Regency, using a survey method. There are 45 respondents taken by Simple Random Sampling Method. Data are analyzed by quantitatively and qualitatively using income analysis (Revenue-Cost Ratio-R/C), household income analysis, and breeder welfare level based on the criteria of the Central Bereu of Statistics (BPS). The results show that the average income of farmers based on cash costs and total costs is IDR 138,882,134.78 per year and IDR 132,405,206.29 per year. Cattle business is feasible and profitable because the ratio of revenue to cash costs and a total cost more than one $(R / C>1)$, namely 1.44 and 1.41 . Cattle business gives the biggest contribution to household income by $94.38 \%$, while the rest comes from on farm, off farm, and non-farm. Based on BPS criteria, 91.11\% of breeder households in Astomulyo Village are in the welfare category.
\end{abstract}

Keywords: Beef cattle farmer, Household welfare, Income analysis 


\section{PENDAHULUAN}

Sektor pertanian menjadi salah satu sekor yang memiliki peranan dalam pembangunan nasional. Hal ini dibuktikan dengan sektor pertanian memiliki kontribusi terbesar kedua dalam Produk Domestik Bruto (PDB) menurut lapangan usaha pada tahun 2013 yaitu sebesar $14,42 \%$ setelah sektor industri pengolahan yaitu sebesar 23,69\% (BPS, 2014). Sektor perternakan merupakan salah satu dari sektor pertanian yang memiliki peranan dalam memenuhi kebutuhan masyarakat akan permintaan konsumsi daging sapi yang semakin tinggi, hal tersebut membuat pemerintah berupaya untuk meningkatkan ketersediaan daging sapi di Indonesia agar permintaan masyarakat akan daging sapi dapat terpenuhi.

Provinsi Lampung menjadi daerah penghasil daging sapi terbesar keempat di Pulau Sumatera sejak tahun 2013 hingga 2017. Kabupaten Lampung Tengah merupakan daerah yang memiliki populasi ternak sapi terbesar di Provinsi Lampung, salah satunya di Kecamatan Punggur. Kecamatan Punggur memiliki daerah dengan populasi ternak sapi terbesar yaitu di Desa Astomulyo sebanyak 987 ekor pada tahun 2016.

Desa Astomulyo menjadi desa yang memiliki tingkat produksi daging sapi yang tinggi dikarenakan banyaknya peternak sapi di desa ini. Rata-rata penduduk di Desa Astomulyo menjadikan usahatani ternak sapi sebagai mata pencaharian peternak selain usahatani. Agar dapat meningkatkan pendapatannya dalam melakukan budidaya ternak sapi, peternak di Desa Astomulyo bergabung ke dalam Kelompok Tani Ternak Limousin yang sudah berdiri sejak tahun 1991.

Kelompok Tani Ternak Limousin memiliki tiga jenis pola pemeliharaan, yakni pola kemitaran, pinjaman, dan mandiri. Kelompok tani ternak yang sudah 28 tahun berdiri melahirkan peternak-peternak baru yang ingin melakukan budidaya ternak sapi, ada dugaan bahwa peternak yang tergabung dalam kelompok ternak ini memiliki pendapatan tinggi yang nantinya akan berdampak pada tingkat kesejahteraannya.

Penelitian mengenai usaha ternak sapi sendiri masih bersifat parsial belum komprehensif seperti penelitian Bancin et al. (2014), Aiba et al. (2018) dan Qinayah et al. (2017) yang hanya meneliti tentang pendapatan peternak sapi atau penelitian Mohammad et al. (2013) yang membahas tentang kesejahteraan peternak sapi. Sehingga perlu adanya penelitian yang membahas secara menyeluruh tidak hanya pendapatan usaha ternak, tapi juga pendapatan rumah tangga hingga kesejahteraan peternak sapi. Oleh sebab itu diperlukan penelitian untuk menganalisis pendapatan usaha ternak sapi anggota Kelompok Tani Ternak Limousin, pendapatan rumah tangga peternak sapi anggota Kelompok Tani Ternak Limousin, dan menganalisis tingkat kesejahteraan peternak sapi anggota Kelompok Tani Ternak Limousin.

\section{MATERI DAN METODE}

\section{Materi}

Penelitian dilakukan di Desa Astomulyo, Kecamatan Punggur, Kabupaten Lampung Tengah. Responden penelitian adalah peternak sapi potong anggota Kelompok Tani Ternak Limousin. Pengambilan sampel dengan menggunakan teknik metode acak sederhana (simple random sampling). Jumlah peternak anggota Kelompok Tani Ternak Limousin adalah 105 orang.Selanjutnya dengan menggunakan rumus Isaac dan Michael (1981) dalam Sugiarto et al. (2003) diperoleh jumlah sampel sebanyak 48 responden. Selanjutnya, data dikumpulkan menggunakan alat bantu kuesioner dengan teknik wawancara. Data yang diperoleh disusun dalam suatu tabulasi, dan dianalisis secara kualitatif dan kuantitatif.

\section{Metode}

\section{a. Pendapatan Usaha Ternak}

Pendapatan usaha ternak dihitung dengan menggunakan rumus sebagai berikut:

$\mathrm{P}=\mathrm{TR}-\mathrm{TC}=(\mathrm{Y} . \mathrm{Py})-(\Sigma \mathrm{Xi} \cdot \mathrm{Pxi}+\mathrm{BTT})$

Keterangan :

$\mathrm{P} \quad$ : Pendapatan (Rp)

TR : Total penerimaan ( $\mathrm{Rp})$

TC : Total biaya (Rp)

$\mathrm{Y}$ : Hasil produksi $(\mathrm{Kg})$

Py : Harga hasil produksi (Rp)

$\mathrm{Xi}$ : Faktor produksi $(\mathrm{i}=1,2,3, ., \mathrm{n})$

Pxi : Harga faktor produksi ke-i (Rp)

BTT : Biaya tetap total (Rp)

Selanjutnya untuk melihat apakah usaha ternak layak atau tidak dengan menggunakan rumus :

$\mathrm{R} / \mathrm{C}=\mathrm{PT} / \mathrm{BT}$

Keterangan :

$\mathrm{R} / \mathrm{C}$ : nisbah penerimaan dan biaya

PT : penerimaan total (Rp)

BT : Biaya total $(\mathrm{Rp})$ 
Pengambilan keputusan adalah :

a. Jika R/C $>1$, maka usaha ternak yang dilakukan layak atau menguntungkan

b. Jika $\mathrm{R} / \mathrm{C}=1$, maka usaha ternak yang dilakukan berada pada titik impas (Break Even Point)

c. Jika $\mathrm{R} / \mathrm{C}<1$, maka usaha ternak yang dilakukan tidak layak atau tidak menguntungkan

\section{b. Pendapatan Rumah Tangga}

Pendapatan rumah tangga adalah keseluruhan pendapatan yang diterima oleh rumah tangga peternak sapi, baik dari usaha ternaknya maupun pendapatan dari luar peternakan sapi. Rumus pendapatan rumah tangga menurut Hastuti dan Rahim (2008) sebagai berikut:

$\mathrm{Prt}=\mathrm{P} 1+\mathrm{P} 2+\mathrm{P} 3+\mathrm{P} 4$

Keterangan :

Prt : Pendapatan rumah tangga (Rp)

$\mathrm{P} 1$ : Pendapatan usaha ternak (Rp)

P2 : Pendapatan usahatani (Rp)

P3 : Pendapatan off farm (Rp)

$\mathrm{P} 4$ : Pendapatan non farm (Rp)

Menurut BPS (2016) terdapat empat golongan yang membedakan masing-masing jumlah pendapatan, yaitu sebagai berikut :

1. Golongan pendapatan sangat tinggi, adalah jika pendapatan rata- rata lebih dari Rp6.000.000,00 per bulan

2. Golongan pendapatan tinggi, adalah jika pendapatan rata-rata antara Rp4.000.000,00 hingga Rp6.000.000,00 per bulan

3. Golongan pendapatan sedang, adalah jika pendapatan rata-rata antara Rp2.000.000,00 hingga Rp4.000.000,00 per bulan

4. Golongan pendapatan rendah, adalah jika pendapatan rata-rata Rp2.000.000,00 per bulan.

\section{c. Tingkat Kesejahteraan}

Kesejahteraan peternak dilihat menggunakan indikator menurut BPS (2014) yang memiliki tujuh indikator yaitu kependudukan, kesehatan dan gizi, pendidikan, ketenagakerjaan, taraf dan pola konsumsi, perumahan dan lingkungan, sosial dan lain-lain.

Indikator kependudukan meliputi jumlah anggota keluarga yang tinggal dalam satu rumah. Kesehatan dan gizi terkait dengan keluhan penyakit, dana kesehatan, dan akses terhadap fasilitas Kesehatan. Pendidikan meliputi jumlah anggota yang dapat membaca dan menulis, pandangan mengenai pentingnya pendidikan, dan lama pendidikan. Ketenagakerjaan mencakup jumlah anggota yang bekerja, pekerjaan tambahan, dan upah yang diterima. Taraf dan pola konsumsi mengenai kecukupan pendapatan keluarga perbulan untuk konsumsi pangan dan nonpangan. Perumahan dan lingkungan mencakup keadaan rumah dan tempat tinggal. Indikator sosial dan lain-lain meliputi kemampuan dalam mengakses wisata dan teknologi.

Klasifikasi kesejahteraan yang digunakan terdiri dari dua klasifikasi yaitu petani dalam kategori sejahtera dan belum sejahtera. Klasifikasi tersebut ditentukan dengan cara mengurangi skor tertinggi dengan jumlah skor terendah kemudian hasilnya dibagi dengan jumlah klasifikasi dari indikator yang digunakan. Rumus penentuan range skor menurut BPS (2014) sebagai berikut:

$$
\mathrm{RS}=\frac{\mathrm{SkT}-\mathrm{SkR}}{\mathrm{JK} 1}
$$

Keterangan:

RS : Range skor

SkT : Skor tertinggi $(7 \times 3=21)$

SkR : Skor terendah $(7 \times 1=7)$

JK1 : Jumlah klasifikasi yang digunakan

Hasil perhitungan tersebut akan diperoleh range skor (RS) sehingga tingkat kesejahteraan rumah tangga peternak sapi yaitu:

1. Jika skor antara 7-14 berarti rumah tangga petani belum sejahtera

2. Jika skor antara15-21 berarti rumah tangga petani sejahtera.

\section{HASIL DAN PEMBAHASAN}

\section{Karakteristik Responden}

Peternak memiliki usia produktif yaitu rata-rata 44 tahun dengan rentang umur 35-50 tahun sebesar $37,78 \%$. Tingkat pendidikan peternak mayoritas sudah tinggi, namun terdapat $17,78 \%$ peternak merupakan lulusan tingkat SD dan telah berumur lanjut, hal ini dikarenakan rendahnya pemahaman akan pentingnya pendidikan dan tingkat kemiskinan yang tinggi pada masa itu. Sebesar 53,33\% peternak memiliki jumlah tanggungan sebanyak 1-2 orang. Pengalaman usaha ternak peternak sebesar $82,22 \%$ yaitu antara 2-7 tahun yang menunjukkan bahwa banyak peternak belum lama melakukan budidaya usaha ternak sapi potong. Mayoritas peternak sudah melakukan pemeliharaan sapi dalam jumlah cukup banyak. Rata-rata peternak 
memelihara sapi potong sebanyak 9 sampai dengan 16 ekor atau sekitar 42,22\%. Sebanyak $80 \%$ peternak memperoleh modal dari pinjaman, baik dari pinjaman bank maupun dari keluarga lainnya.

\section{Keadaan Umum Kelompok Tani Ternak Limousin}

Kelompok tani ternak ini memiliki 3 pola pemeliharaan yaitu pola mandiri dimana dilakukan kerjasama dengan PT GGLC dalam upaya invesatasi sapi PIR, pola pinjaman dengan mempermudah peternak anggota untuk meminjam bank guna modal usaha budidaya ternak sapi, dan pola mandiri dimana peternak melakukan usaha ternak tanpa melakukan pinjaman bank.

\section{Kegiatan Usaha Ternak Sapi}

Usaha ternak sapi potong terdiri dari empat kegiatan yaitu pemberian pakan, pemeliharaan kandang, pengendalian penyakit dan vaksisnisasi, dan pemasaran. Seluruh peternak responden menggunakan tenaga kerja dalam keluarga untuk melakukan kegiatan usaha ternak sapi potong.

\section{Penggunaan Input Sapi}

Peternak dengan jumlah rata-rata kepemilikan 13 ekor sapi (per usaha ternak), peternak mengeluarkan biaya bakalan sebesar Rp. 230.977.755,37 per tahun dengan harga ratarata bakalan sapi Rp. $18.420 .811,15$ per ekor. Bakalan sapi yang dibeli adalah sapi peranakan yang memiliki postur tubuh terutama kaki yang bagus agar dapat menahan bobot tubuh yang nantinya akan terus ditambah. Jenis bakalan sapi yang dipakai adalah Limousin dan Simmetal.

Pakan yang digunakan peternak adalah kulit singkong, kulit nanas, dan onggok. Peternak juga menambah konsentrat sebagai pakan tambahan. Takaran yang diberikan untuk pakan per hari adalah $20 \mathrm{~kg}$ per hari untuk satu ekor sapi dengan perbandingan antar pakan yang seimbang 5:5:5:5. Biaya pakan yang dikeluarkan sebesar Rp. 63.210.253,30 per tahun untuk per usaha ternak.

Vitamin yang diberikan peternak ada dua macam, yaitu injektamin dan B-kompleks dengan jumlah biaya untuk pembelian vitamin yang dikeluarkan peternak adalah sebesar Rp. 245.533,33 per tahun untuk per usaha ternak. Sedangkan obat-obatan yang diberikan peternak adalah obat flu, kaki pincang, gatal, cacingan, dan kulit dengan biaya obat-obatan sebesar Rp. 651.555,56 per tahun untuk per usaha ternak.

Biaya lain-lain yang dikeluarkan peternak selama satu tahun meliputi biaya pajak berupa pajak luas kandang sebesar Rp. 25.722,22, biaya listrik untuk menerangi lampu di kandang sebesar Rp. 338.666,67 dan biaya bunga bagi peternak yang meminjam uang di Bank BNI dengan bunga 7\% per tahun sebesar Rp. 8.120.000,00.

Peternak dalam melakukan kegiatan usaha ternak menggunakan tenaga kerja dalam keluaga, dimana biaya TKDK sebesar Rp. 4.029.666,67 per tahun untuk per usaha ternak. Peternak masih menggunakan tenaga kerja dalam keluarga dikarenakan mayoritas usaha ternak peternak responden masih dalam lingkup usaha kecil.

Biaya penyusutan kandang dan alat yang dikeluarkan peternak dalam satu tahun sebesar Rp2.447.359,05. Kandang memiliki nilai penyusutan terbesar yaitu $\mathrm{Rp} 2.264 .418,48$ per tahun disebabkan biaya dalam pembuatan kandang yang besar. Alat-alat yang digunakan dalam kegiatan usaha ternak meliputi lori, sekop, garu, selang, suntikan, tempat makan, sapu lidi, dan ember.

\section{Analisis Pendapatan Usaha Ternak Sapi}

Berdasarkan hasil penelitian, produksi rata-rata sapi potong pada peternak Kelompok Tani Ternak Limousin adalah $10.373,13 \mathrm{~kg}$ per tahun dengan harga jual rata-rata sebesar Rp. 43.533,33 per kg, sehingga penerimaan ratarata peternak responden adalah sebesar Rp. 451.576.877,63 per tahun.

Berdasarkan data yang disajikan pada Tabel 1, usaha ternak sapi pada Kelompok Tani Ternak Limousin dengan kepemilikan sapi tiga belas ekor (per usaha ternak) dan satu ekor (per ekor)sudah menguntungkan dan layak untuk diusahakan dengan $\mathrm{R} / \mathrm{C}$ ratio 1,44 atas biaya tunai dan 1,41 atas biaya total, dimana setiap Rp. 10.000,00 biaya yang dikeluarkan oleh peternak tersebut mendapatkan keuntungan sebesar Rp. 10.440,00 atas biaya tunai dan Rp. $10.410,00$ atas biaya total. Hasil ini sejalan dengan penelitian oleh Rahayu (2017) yang menunjukkan bahwa usaha ternak sapi potong memiliki R/C ratio lebih dari satu yang berarti usaha ternak sapi potong tesebut layak untuk diusahakan dan menguntungkan.

\section{Analisis Pendapatan Rumah Tangga}

Pendapatan rumah tangga peternak berasal dari jumlah pendapatan on farm (usaha ternak dan usahatani), off farm, dan non farm. Pendapatan rumah tangga merupakan jumlah keseluruhan dari pendapatan yang diterima oleh seluruh anggota keluarga baik dari kepala keluarga, istri, anak, dan anggota keluarga lainnya.

Peternak sapi tidak hanya memperoleh pendapatan dari usaha ternak saja. Pendapatan 
selain dari penjualan sapi potong namun yang masih dalam lingkup pertanian yang diperoleh peternak responden adalah sebagai petani sawah dengan perolehan pendapatan Rp. 1.888.444,44 per tahun. Pendapatan off farm merupakan pendapatan yang diperoleh dari kegiatan seperti buruh tani dan juga dari penjualan kotoran sapi. Perolehan pendapatan dari off farm adalah Rp. 1.379.111,11 per tahun. Peternak responden memperoleh pendapatan non farm dari penghasilannya yang berkerja sebagai tukang ojek, pekerja bengkel, pemilik warung, karyawan, dan buruh pabrik dengan jumlah Rp. 5.000.000 per tahun. Pendapatan rumah tangga peternak disajikan pada Tabel 2.

Tabel 2 menyajikan perolehan pendapatan dari usaha ternak memiliki kontribusi yang sangat tinggi. Hal ini yang menyebabkan peternak responden menjadikan usaha ternak sapi sebagai mata pencaharian utamanya dalam memperoleh pendapatan. Tingginya kontribusi usaha ternak dalam pendapatan keluarga sejalan dengan penelitian yang dilakukan oleh Rahayu (2013) dan Hoddi et al. (2011) yang menyatakan bahwa usaha ternak memiliki kontribusi yang tinggi dalam upaya untuk menambah pendapatan rumah tangga lebih dari 50 persen.

Rata-rata perolehan pendapatan rumah tangga peternak responden sebesar Rp. 12.262.474,19 per bulan. Berdasarkan penggolongan tingkat pendapatan oleh BPS
(2016), pendapatan rumah tangga peternak termasuk dalam golongan pendapatan sangat tinggi yaitu lebih dari Rp. 6.000.000,00 per bulan. Hal ini dikarenakan mayoritas peternak melakukan usaha ternak dengan jumlah sapi lebih dari 10 ekor, dimana satu ekor sapi dapat memberikan keuntungan bersih antara Rp. 500.000,00 sampai dengan Rp. 1.300.000,00 per bulan. Perolehan pendapatan bersih usaha ternak yang tinggi ini menjadikan peternak memperoleh pendapatan rumah tangga yang sangat tinggi. Hal ini selaras dengan penelitian yang dilakukan oleh Rosdiana (2018) pendapatan rumah tangga peternak susu kambing etawa termasuk dalam golongan pendapatan sangat tinggi yaitu sebesar Rp. 8.687.800,00 per bulan.

\section{Tingkat Kesejahteraan}

Kriteria tingkat kesejahteraan menurut Badan Pusat Statistik (2014) terdapat tujuh indikator, yaitu kependudukan, kesehatan dan gizi, pendidikan, ketenagakerjaan, taraf dan pola konsumsi, perumahan dan lingkungan, sosial dan lain-lain. Tingkat kesejahteraan rumah tangga petani dikelompokkan menjadi 2 kategori yaitu rumah tangga petani belum sejahtera jika skor yang diperoleh antara 7-14 dan rumah tangga sejahtera jika skor yang diperoleh antara 15-21. Hasil perhitungan indikator kesejahteraan menurut BPS (2014) dapat dilihat pada Tabel 3.

Tabel 2. Rata-rata pendapatan rumah tangga peternak per usaha ternak.

Average income of livestock farmers per livestock business.

\begin{tabular}{|c|c|c|c|c|c|}
\hline & $\begin{array}{l}\text { erolehan Pendapatan } \\
\text { Earnings Income }\end{array}$ & $\begin{array}{l}\text { Pendapatan } \\
\text { Income } \\
\text { (Rp/Tahun) }\end{array}$ & $\begin{array}{r}\text { Kont } \\
\text { Inco }\end{array}$ & $\begin{array}{l}\text { Ibusi Pen } \\
\text { ne Contr } \\
(\%)\end{array}$ & $\begin{array}{l}\text { dapatan } \\
\text { ibution }\end{array}$ \\
\hline & Usaha ternak & $138.882 .134,78$ & & & 94,38 \\
\hline & On Farm & $1.888 .444,44$ & & & 1,28 \\
\hline & Off Farm & $1.379 .111,11$ & & & 0,94 \\
\hline & Non Farm & $5.000 .000,00$ & & & 3,40 \\
\hline & Total & $147.149 .690,33$ & & & 100,00 \\
\hline Tabel & $\begin{array}{l}\text { 3. Indikator kesejahtera } \\
\text { Welfare indicators ac }\end{array}$ & $\begin{array}{l}\text { lan Pusat Statistik } \\
\text { Central Statistics }\end{array}$ & $\begin{array}{l}\text { 2014). } \\
\text { gency (2014). }\end{array}$ & & \\
\hline $\begin{array}{l}\text { No. } \\
\text { No. }\end{array}$ & & & $\begin{array}{c}\text { Jumlah (orang) } \\
\text { Total (people) }\end{array}$ & $\%$ & $\begin{array}{c}\text { Kategori } \\
\text { Categories }\end{array}$ \\
\hline 1. & Kependudukan/Populc & & 45 & 100,00 & Cukup \\
\hline 2. & Kesehatan dan Gizi/H & tion & 33 & 73,30 & Baik \\
\hline 3. & Pendidikan/Education & & 42 & 95,45 & Baik \\
\hline 4. & Ketenagakerjaan/Emp & & 30 & 66,67 & Cukup \\
\hline 5. & $\begin{array}{l}\text { Taraf dan pola konsun } \\
\text { pattern }\end{array}$ & on level and & 40 & 88,89 & Baik \\
\hline 6. & $\begin{array}{l}\text { Perumahan dan lingku } \\
\text { environment }\end{array}$ & and & 44 & 97,78 & Baik \\
\hline 7. & Sosial dan lain-lain/ $S$ & & 21 & 46,67 & Cukup \\
\hline
\end{tabular}


Berdasarkan Tabel 3 disajikan 4 (empat) indikator berada pada kategori baik dan 3 (tiga) indikator berada pada kategori cukup. Indikator kesehatan dan gizi, pendidikan, taraf dan pola konsumsi, serta perumahan dan lingkungantergolong pada kategori baikdengan skor yang tinggi yaitu 3. Indikator kependudukan, ketenagakerjaan, serta sosial tergolong ke dalam kategori cukupdengan nilai skor yaitu 2. Skor dari setiap indikator kesejahteraan kemudian dijumlahkan sehingga diperoleh total skor yang menunjukkan rumah tangga petani petani sapi termasuk ke dalam golongan sejahtera atau belum sejahtera.

Hasil perhitungan menunjukkan sebesar 91,11 persen atau sebanyak 41 responden termasuk dalam kategori sejahtera, namun sebesar 8,89 persen atau sebanyak 4 responden belum sejahtera dikarenakan belum mampu untuk memenuhi skor dalam setiap indikator dalam kategori tingkat kesejahteraan menurut BPS (2014).

\section{SIMPULAN}

Simpulan penelitian ini adalah peternak sapi pada Kelompok Tani Ternak Limousin memperoleh pendapatan atas biaya tunai usaha ternak sapi sebesar Rp138.882.134,78 per tahun dan pendapatan atas biaya total sebesar Rp132.405.206,29 per tahun dengan R/C atas biaya tunai dan total sebesar 1,44 dan 1,41 yang berarti usaha ternak tersebut menguntungkan dan layak diusahakan. Pendapatan rumah tangga peternak sapi potong di Desa Astomulyo tergolong sebagai pendapatan yang sangat tinggi sebesar Rp12.468.961,37 per bulan dengan kontribusi terbesar berasal dari kegiatan on farm usaha ternak sapi $(94,47 \%)$. Mayoritas rumah tangga peternak sapi potong atau sebesar 91,11 persen di Desa Astomulyo masuk dalam kategori sejahtera.

\section{DAFTAR PUSTAKA}

Aiba A., J.C. Loing, B. Rorimpandey, L.S. Kalangi. 2018. Analisis pendapatan usaha peternak sapi potong di Kecamatan Weda Selatan Kabupaten Halmahera Tengah. $J$. Zootek, 38(1):149-159.

Badan Pusat Statistik. 2014. Indikator Kesejahteraan Rakyat 2007. Badan Pusat Statistik. http://bps.go.id. Diakses 10 Juni 2019.

2016. Penggolongan

Pendapatan Penduduk. http://bps.go.id. Diakses 10 Juni 2019.
Bancin, S., Hasnudi dan U. Budi. 2014. Analisis pendapatan peternak sapi potong di Kecamatan Siempat Nempu Hulu Kabupaten Dairi. J. Peternakan Integratif, 2 (1): 79-90.

Hastuti D. dan Rahim A. 2008. Pengantar, Teori, dan Kasus Ekonomik Pertanian. Penebar Swadaya. Jakarta.

Hoddi, A. H., M.B. Rombe, dan Fahrul.2011. Analisis Pendapatan Peternakan Sapi Potong Di Kecamatan Tanete Rilau, Kabupaten Barru. J. Agribisnis, 10(3):98109.

Qinayah M., Hastang dan S.N. Sirajuddin. Tingkat pendapatan peternak sapi potong pada skala usaha yang berbeda di Desa Mattirowalie Kecamatan Tanete Riaja Kabupaten Barru. Prodising Seminar Nasional Peternakan 3 Tahun 2017 Universitas Hasanuddin. 18 September 2017:257-263. Makassar.

Rahayu. 2017. Analisis Pendapatan Peternak Sapi Potong di Desa Mattirowalie Kecamatan Tanete Riaja Kabupaten Barru. Skripsi. Universitas Hasanuddin. Makassar.

Rosdiana, I. 2018. Analisis Pendapatan dan Kesejahteraan Rumah Tangga Peternak Susu Kambing Etawa (Studi Kasus Laboratorium Desa Universitas Lampung Di Desa Sungailangka Kecamatan Gedong Tataan Kabupaten Pesawaran). Skripsi. Fakultas Pertanian Universitas Lampung. Bandar Lampung.

Sugiarto, D. Siagian, D. dan Lasmono. 2003. Teknik Sampling. PT. Gramedia Pustaka Utama. Jakarta.

Trigestianto M, Nur S. dan Sugiarto M. 2013. Analisis tingkat kesejahteraan peternak sapi potong di Kabupaten Purbalingga). Abstrak. J. Ilmiah Peternakan. 1(3): 11581164 